\title{
Is Corruption Bad for Environmental Sustainability? A Cross-National Analysis.
}

\author{
Stephen Morse $^{1}$
}

\begin{abstract}
This paper explores the hypothesis that higher levels of corruption are detrimental to environmental sustainability. It does this by employing the Environmental Sustainability Index (ESI) and its component variables and indicators as promoted by the World Economic Forum and the Corruption Perception Index (CPI) created by Transparency International (TI). Both the CPI and ESI were shown to be statistically significantly related to income (proxied as GDP/capita) such that environmental sustainability declined with decreasing income while corruption worsened. The ESI for 2002 was also divided into indicators representing pressure, state, impact and response (i.e., the PSIR framework), and each of these were regressed onto a 'residual CPI' (CPI of 2002 with the influence of income removed). The results suggest that for the most part the pressure, state and impact indicators of the ESI are not correlated with 'residual' CPI. The only statistically significant relationships with 'residual CPI' were for those of the response indicators of the ESI, although even here the R2 values were low $(<20 \%)$. Corruption was found to reduce any positive contribution from the response indicators towards environmental sustainability. However, great care needs to be taken when drawing conclusions from the sort of highly aggregated (spatially as well as mathematically) indices as the ESI and CPI.
\end{abstract}

Key Words: Corruption Perception Index; Environmental Sustainability Index.

\section{INTRODUCTION}

Corruption, defined here as the "abuse of public power for private gain" (World Bank 1997), has long been highlighted as an important consideration in development, and today is part of the wider 'good governance' agenda promoted by aid agencies (Doig and McIvor 1999). The assumption is straightforward. Corruption can result in the diversion of resources from the public good to private consumption and overall result in losing the impacts that were intended to be of wider benefit. Indeed Doig and McIvor (1999) state that corruption "has distorted development priorities, led to massive human and financial capital flight, and undermined social and political stability ... corruption is deeply damaging to the social and political fabric, to investment, and to economic growth." Given this statement it is no surprise that Hisamatsu (2003) states "it is difficult to overstate the economic and social significance of corruption".

Causes of corruption are said to be many (World Bank 1997, Goudie and Stasavage 1998) but can broadly be divided into three aspects:

1. Opportunity. Included here will be aspects such as demand from foreign firms (Hisamatsu 2003) and 'spaces of corruption' where there is a lack of transparency combined with power (Zemanovicova 2002) and where there are "highly distorted policies" that create gaps between demand and supply (World Bank 1997).

2. Motive. This may be especially enhanced if salaries and living conditions of officials with opportunity are relatively poor (World Bank 1997). 
3. Probability of being caught and punished. If this is low then corruption is likely to be encouraged. It should also be noted that corruption may actually be tolerated by citizens as a means of 'making things happen'.

Corruption has not only been linked to social and economic development, but also to environmental sustainability (Lopez and Mitra 2000, Damania et al. 2003, Welsch 2004). While corruption is not environmentally destructive in a general sense (Robbins 2000) poor governance results in bad policy formulation, management, and enforcement, and this can become apparent through problems with environmental sustainability (Damania et al. 2003). Yet while there are many assumed causeeffect relationships between corruption and environmental sustainability there are few empirical analyses. One qualitative example focused on environmental regulation in the New York waste industry and how this interacts with organized crime is provided by Carter (1997). There are also examples that take a more quantitative approach by correlating measures of corruption with indicators of environmental sustainability in much the same way as others have tried with corruption and economic performance (Mauro 1995, Hall and Jones 1999). Since the turn of the century this has been facilitated somewhat by the emergence of the 'high-profile' Environmental Sustainability Index (ESI) for nation states. The ESI, first published in 2001 and subsequently in 2002 and 2005, has seen an increasing popularity at least in the popular media (Morse 2004, Morse and Fraser 2005) and has been overtly linked in the press to the rule of law:

"Finland and Norway have the most environmentally sustainable economies. The Environmental Sustainability Index is an assessment of dozens of variables that influence the environmental health of economies. One of the strongest determinants, besides wealth, seems to be good governance including a broad commitment to the rule of law" Economist (2002).

The ESI is by no means the only index or indicator of sustainability (Sutton and Costanza 2002), and an approach also gaining in interest is the estimation of Critical Natural Capital (CNC). The increasing popularity of the ESI is in part related to the fact that it is promoted by the powerful World Economic Forum (WEF), and its release coincides with highprofile WEF meetings. The ESI is a thorough index in the sense that the rationale, methodology, and component data sets are carefully laid out in widely available documentation (www.ciesin.columbia. edu/indicators/ESI/). This greatly facilitates the use of the ESI for relating environmental sustainability to economic performance (Morse and Fraser 2005) as well as corruption. Corruption, however unlike economic performance which can be proxied with measures such as gross domestic product (GDP) and gross national product (GNP), is a complex human behavior that is notoriously difficult to measure precisely because its very nature makes it opaque (Lambsdorff 1999, Hisamatsu 2003). Those benefiting from corruption are unlikely to say so and even more unlikely to say how much they receive. Those on the giving end may be less reticent to talk about the extent of corruption, but there is a danger of them exaggerating their problems by confounding difficult bureaucracies and different ways of doing business with corruption. As a result, empirical analysis of corruption is a relatively new endeavor (Lambsdorff 1999), but even so national measures typically based on perceptions of its prevalence do exist and the ESI includes one of them (World Bank Corruption Survey) as a component. A more widely reported metric is the Corruption Perception Index (CPI) published each year by the Berlin-based Transparency International (TI). Both of these indices reflect an increasing desire to measure complex characteristics of society and to present the results in a comparative format, in this case league tables.

In a recent and pioneering contribution Welsch (2004) uses the cross-national data available in the ESI 2002 data sets to explore the relationship between air and water pollution and corruption. For the latter he employed the World Bank Corruption Survey data in the ESI data set. Both 'state' (ambient) and 'pressure' (emissions) were included ${ }^{[1]}$, and the results suggest that there are two effects:

1. A direct effect, such that corruption interferes with monitoring, enforcement, etc. Hence, more corruption unambiguously corresponds with more pollution. As stated in the ESI 2005 report (Esty et al. 2005), "corruption contributes to lax enforcement of environmental regulations and an ability on the part of producers and consumers to evade responsibility for the environmental harms they cause". 
2. An indirect effect, as corruption is negatively related to prosperity, which in turn has more complex relationships with various measures of pollution. For low income countries an increase in GDP may increase pollution but there is a turning point beyond which increasing prosperity reduces pollution (Grossman and Krueger 1995).

As a result, "the effect of corruption on pollution is particularly strong in low income countries. Reducing corruption is therefore especially important for the less developed regions" (Welsch 2004). However, the linkage between 'state' and 'pressure' was unclear for some pollutants as emissions kept increasing beyond the point where ambient levels had peaked. Welsch (2004) puts this down to poor data quality for emissions such that values are underestimated, and suggests that this bias could be at least in part a result of corruption. Hence all of his subsequent analyses and conclusions deal only with state indicators. But how valid are such comparisons, even if they are addressing important questions, founded on highly aggregated indices expressed at national level? After all, deriving single values of environmental sustainability and corruption for a nation would appear to be simplistic in the extreme.

This paper aims to critically dissect the assumed relationship between corruption (independent variable; CPI) and environmental sustainability (dependent variable; ESI). Can such analyses yield valid insights into such an hypothesized relationship and what are the limitations inherent within such cross-national comparisons using simplified data sets? If insights can be derived then what are they?

Rather than focus solely on the published values of the ESI the analysis will go one step further by dissecting the ESI into its Pressure-State-ImpactResponse (PSIR) components. As will be discussed later, one of the advantages of the ESI is that this is a relatively easy step to achieve given the way in which the ESI is presented by its creators. The PSIR model was popular in the 1990s (Berger 1997, Gallopin 1997, Mortensen 1997, Crabtree and Bayfield 1998, Guy and Kibert 1998) and indeed was adopted by the United Nations following the first Earth Summitt in 1992 although it has since been dropped. While the PSIR framework has the advantage of highlighting cause-effect in sustainability it has been criticized for promoting a linear and mechanical thinking (Gallopin 1997, Spangenberg and Bonniot 1998). Nevertheless, it is employed here to see whether the relationship between corruption and environmental sustainability differs across these components.

\section{CORRUPTION PERCEPTION INDEX (CPI)}

Transparency International (TI), the founder of the Corruption Perception Index (CPI), is said to be "the prime global source of information on, and analysis of, corruption in all of its forms" (Davies 2004), and as such is highly respected worldwide (www. transparency.de). The CPI is based upon a perception of corruption amongst a particular group (mostly Northern-based business people, albeit described in the TI reports as 'well-informed people') towards countries with which they have experience (Lambsdorff 2002). This group has a particularly intricate relationship with corruption given that they may be perceived as a lucrative source of bribes by potential receivers and this may well generate a biased perspective towards corruption. However, it could also be argued that it is subjective perception of corruption that influences factors such as investment (Mauro 1995).

Data for the CPI are taken from a number of independent surveys of the perception of corruption including those of the World Bank. For example, the CPI of 2002 used data from the following sources:

- World Economic Forum corruption reports

- Institute for Management Development, Lausanne

- Pricewaterhouse Coopers

- World Bank's World Business Environment Survey

- Economist Intelligence Unit

- $\quad$ Freedom House, Nations in Transit

- Political and Economic Risk Consultancy, Hong Kong

- Gallop International on behalf of Transparency International 


\section{- State Capacity Survey by Columbia University}

Most of these sources have their own index of corruption and a ranking of nations based on that index. Methodologies do vary between them, including the group sampled and the questions asked about corruption. Some only have results for one year while others have several years of data. The way in which the survey results are combined into the CPI is complex; details can be found in Lambsdorff (2002). The result is an aggregated index in the sense that it is comprised of other indices of corruption. Each country is allocated a value ranging between 0 (most corrupt) and 10 (least corrupt).

The CPI has its faults. Allegations of a Northernbias have already been mentioned, but is it realistic to extrapolate a perception gained by this group interacting with maybe relatively few people, albeit in important and powerful positions, to a whole country? Even so, it is generally assumed that the CPI is one of the best measures of corruption currently in place largely because it utilizes such a wide range of sources rather than relaying on just one (Wilhelm 2002).

\section{ENVIRONMENTAL SUSTAINABILITY INDEX (ESI)}

The Environmental Sustainability Index (ESI) is also an aggregated index, but of a different nature then the CPI. Here the aggregation results from combining data sets encompassing diverse aspects of environmental sustainability from ambient pollution and emissions of pollutants to impacts on human health and being a signatory to international agreements. Values of the ESI have been published for 2001, 2002, and 2005. The gap between 2002 and 2005 was deliberate and reflected a view amongst the creators of the index that it was not necessary to publish the ESI every year.

Values of the ESI for each country vary between 0 (most unsustainable) to 100 (most sustainable), and like the CPI the results for each country are published in the form of a league table. The ESI methodology can be found in the various reports of the ESI (http://sedac.ciesin.columbia.edu/es/esi/). In essence, it is an aggregation process from variables (raw data sets) combined into indicators (aggregates of variables), which in turn are placed into one of five components and then averaged to generate the ESI. An important strength of the ESI is the presentation of all this rich information alongside the final values of the index (Jesinghaus 2000). As one of the founders of the index points out: "The true value [of the ESI] is the ability to break down the score on an issue by issue basis" (Esty 2005 New Scientist).

A summary of the number of variables and indicators in each of the five components comprising the ESI for 2001, 2002, and 2005 are shown in Table 1. More important for this paper is the nature of the variables, and these have been subject to some evolution since 2001 .

Table 2 illustrates the variables included in the ESI 2001, 2002, and 2005, and how these have changed. In some cases, new variables were introduced while others were omitted. For example, ECORISKwas introduced in 2005 while SOIL only appeared in 2001 and has since been dropped. The same is true of the indicators. The indicator CAPMAI (regulation and management) was included in 2001 but since dropped, although two of its component variables [PRAREA (protected land area under protected status) and EIA (number of sectoral EIA guidelines)] were kept and transferred to another indicator, CAPGOV (environmental governance). While the flexibility is to be applauded, these changes make it difficult to compare the ESI across years.

Aggregation within the ESI is entirely in terms of the relatedness of the variables to the indicator rather than amongst themselves. Hence, while variables within an indicator may be expected to be correlated this may not necessarily be the case. For example, under SYSAIR (air quality) there are four variables in 2005 (three variables in 2001 and 2002): urban NO2, urban SO2, urban TSP, and INDOOR. The first three are employed by Welsch (2004) and could be related to pressure such as number of petrol and diesel vehicles (included as a variable under the 'reducing air pollution' indicator); the fourth is more a function of the use of coal, charcoal, and wood burning. Other indicators have variables that are all related. For example, the indicator 'reducing population pressure' has variables for population change and fertility rate. These two variables are, in essence, cause-effect as fertility rate is one driver for population change. But many of the indicators 
Table 1. The number of indicators and variables comprising the Environmental Sustainability Index (ESI) in 2001, 2002, and 2005.

\begin{tabular}{|c|c|c|c|c|c|c|}
\hline \multirow[b]{3}{*}{ Component } & \multicolumn{2}{|c|}{ ESI 2001} & \multicolumn{2}{|c|}{ ESI 2002} & \multicolumn{2}{|c|}{ ESI 2005} \\
\hline & \multicolumn{2}{|c|}{ Number of } & \multicolumn{2}{|c|}{ Number of } & \multicolumn{2}{|c|}{ Number of } \\
\hline & indicators & variables & indicators & variables & indicators & variables \\
\hline Environmental systems (SYSTEM) & 5 & 13 & 5 & 13 & 5 & 17 \\
\hline Reducing environmental stresses (STRESS) & 5 & 15 & 5 & 15 & 6 & 21 \\
\hline Reducing human vulnerability (VULNER) & 2 & 5 & 2 & 5 & 3 & 7 \\
\hline Social and institutional capacity (CAP) & 7 & 22 & 5 & 22 & 4 & 24 \\
\hline Global stewardship (GLOBAL) & 3 & 12 & 3 & 13 & 3 & 7 \\
\hline Total & 22 & 67 & 20 & 68 & 22 & 76 \\
\hline
\end{tabular}

do not include variables with such a relationship. Given the diversity of the variables and the obvious cause-effect between some of them, it is perhaps surprising that there is no adherence to a PSIR model in any of the ESIs published to date. For the purpose of this paper the PSIR model provides a convenient categorization, and hence Table 2 also includes a judgment by the author as to whether the variables are pressure, state, impact, or response. It should be stressed that while some variables can clearly be placed into one of these categories [e.g., SYSAIR in 'state' and STRAIR (reducing air pollution) in 'pressure')] it is something of a subjective judgment.

The ESI has received some criticism since its first release in 2001 (Jesinghaus 2000, The Ecologist 2001). First, it has been pointed out with some justification that the selection of the variables that make up the ESI is a subjective process and hence the ESI is largely reflecting what its creators feel is important. So there is potentially the same sort of bias as is inherent in the CPI. Given that there is a preponderance of variables having a strong positive correlation with wealth, it could then be argued that the ESI is biased in favor of the richer countries (The Ecologist 2001). Second, as Welsch (2004) points out with his problems interpreting the pressure indicators, there are concerns over the quality of the data that are employed. Only single values for each variable are used for each country and, as with the $\mathrm{CPI}$, one can question whether this is realistic or desirable. For some variables, such as membership of an international agreement to protect the environment, the values are likely to be both accurate and reasonable at the national level. However, is it realistic to have a single value for $\mathrm{SO} 2$ concentration in the urban atmosphere? What about spatial and seasonal differences? Allied to these concerns is the use of imputation to fill in 
Table 2. Indicators and variables included in the Environmental Sustainability Index (ESI) of 2001, 2002, and 2005.

Please see the web version of this table

missing variables gaps for some countries. For a more detailed discussion of these points see Morse (2004).

In fairness to the creators of the ESI, it does need to be stressed that other approaches to measuring sustainability are not without their own limitations. For example, the CNC approach mentioned earlier begins by identifying the characteristics of natural capital in the ecosystem (quantity and quality) and how these relate to ecosystem (e.g., a forest) function (Ekins et al. 2003, Ekins and Simon 2003). Assuming that an economic activity (e.g., deforestation for agriculture or timber) will impact the ecosystem in quantitative (number of trees logged) and/or qualitative (tree species logged or damage caused while logging) terms then this can be estimated and the results compared with an assumption as to what is required for sustainability. In effect, the approach defines both the minimum quantity of natural capital necessary for continued function (e.g., the size and nature of forest) and the maximum pressure (e.g., maximum rate of logging of species) that the natural capital stock (the forest) can tolerate while maintaining all its functions. The difference between the actual levels and what is deemed to be adequate for sustainability is referred to as the Sustainability Gap (SGAP). The approach can be applied at local, national (Deutsch et al. 2003, Ekins and Simon 2003), regional (De Groot et al. 2003), and global scales. However, while the CNC has an appeal it also suffers from disadvantages that in part mirror those of the ESI. For example, the CNC is highly dependent upon good quality data at the ecosystem scale employed in the analysis as well as a good understanding of the link between ecosystem form and function. Also, despite the apparent objectivity of the CNC there is still some underlying subjectivity. For example, with the CNC much depends upon what is meant by the term critical. This may be a relatively straightforward process in terms of biophysical function (e.g., a forest absorbing $\mathrm{CO}_{2}$ ), but what about ethical and social perspectives, and whose values should be the ones employed to define critical? Should local perspectives be allowed to dominate or should the wider national or global interests be the overriding concern? These are essential concerns in the application of the CNC for policy making and management (Chiesura and de Groot 2003)

Despite the limitations of the ESI it has been employed in this analysis for a number of reasons. First, the values of the ESI have been published for three years with the most recent being in 2005 . Second, the values of the ESI indicators are available for a relatively large sample of countries (146 in 2005). Third, the ESI incorporates indicators of impact and response as well as state and pressure. This allows for a wider exploration of relationship to corruption.

\section{METHODS}

\section{Comparison of ESI, CPI, and income}

Between 2000 and 2005 the CPI and the ESI have been employed in their raw form (i.e., the values as published by TI and in the ESI reports, respectively). However, given that there are differences in availability of the ESI and CPI across countries, the data set employed when comparing the CPI to other variables is more limited (sample size $=64$ ). The CPI was not available for 2005 at the time of writing, therefore ESI 2005 is compared against CPI 2004.

GDP per capita was employed as a proxy indicator of income. However, there is a complication with the time-lag in data employed for the ESI and CPI. The published values of the ESI are based on data collected over previous years, while CPI is based on the perception of a previous experience. As a result the values for GDP per capita (adjusted for Purchasing Power Parity, PPP) used in the analyses are those published in the 2002 Human Development Report (UNDP 2002) and used to calculate the Human Development Index (HDI) 
published in that document. The real GDP per capita values are for 2000 (base year is 1996). Analysis was via single regression.

\section{PSIR components}

For the more detailed analysis based on the PSIR components of the ESI, the data for ESI 2002 and CPI 2002 were employed (sample size $=95$ ). The categorization of ESI 2002 indicators is shown in Table 2. Most of the indicators and variables fall into the response category closely followed by pressure. These two components together comprise $74 \%$ of the 68 variables in the ESI 2002. The zvalues of the ESI indicators published in the 2002 report were used for the analyses, not the raw data. The z-values for each of the 20 indicators are found by averaging the $\mathrm{z}$-values for the variables that comprise that indicator. For example, taking the first indicator of Table 2, SYSAIR is found by averaging the z-values of the variables $\mathrm{NO} 2, \mathrm{SO} 2$ and TSP (INDOOR was not included in ESI 2002). The zvalues for the variables are found in one of two ways depending upon the assumed direction of the variable for sustainability. If higher values of the variable are deemed to be good [e.g., dissolved oxygen concentration in water, GMS_DO, which is part of the SYSWQL (water quality) indicator] then the $\mathrm{Z}$-value is given by:

z-value $=($ country value - mean $) /$ standard deviation

The $\mathrm{z}$-value will increase with the country value, and a country value less than the mean will yield a negative $\mathrm{z}$-value.

If high values are deemed to be bad for sustainability (e.g., suspended solids in water, GMS_SS, also part of SYSWQL) then the $\mathrm{z}$ value is given by:

z-value $=($ mean - country value $) /$ standard deviationmean

In this case, a high value for a country (i.e., one greater than the mean) will result in a negative $z$ value. Whichever is used the result is the same; the higher the value of the indicator then the better the sustainability (high values are good while low values are bad).

It should be noted that in the ESI 2002 report some variables are transformed to logarithms before standardizing (the criterion is the degree of skewness of the variable), and there is some capping of variables so as to remove low and high extremes using percentiles. Once the $\mathrm{z}$-values have been found for all of the variables in an indicator they are averaged so that the higher the $\mathrm{z}$-value for an indicator the better the sustainability.

Analysis of the relationship between the PSIR indicators and CPI 2002 was via simple linear regression with the indicator $\mathrm{z}$-values as the dependent variable.

\section{RESULTS}

\section{Income, corruption, and the ESI}

CPI 2002 plotted against GDP per capita for 2000 is provided in Figure 1 (note that higher values of the CPI relate to less corruption). The relationship between the two variables is highly significant with an $\mathrm{R}^{2}$ of $80 \%$, and GDP per capita increases with decreasing perceptions of corruption. This relationship between corruption and economic performance has long been known. Mauro (1995) and Welsch (2004), among others, have taken this to mean that corruption decreases economic performance which in turn drives down income. There are various explanations but maybe the simplest is that corruption leads to poor decision making amongst corrupt officials as effort is geared towards rent-seeking rather than production. Another possibility is that investment from foreignbased companies is less where corruption is perceived to be greatest.

Income can also be related to environmental sustainability, or at least as it is presented in terms of the ESI. Figure 1 includes a plot of published ESI 2002 values for each country against income. Again, the relationship is positive such that the ESI increases (sustainability improves) with increasing income. This positive relationship between the ESI and income has attracted some criticism of the ESI as a measure of environmental sustainability (Morse 2004, Morse and Fraser 2005). Note how poor performers in economic terms are more uniform in terms of their ESI compared to the richer countries. There is also some visual sense of the ESI first decreasing (sustainability worsens) with increasing wealth before increasing again in line with the conclusions of Grossman and Krueger (1995) and others, although the evidence is hardly compelling. 
Fig. 1. GDP per capita 2000 (adjusted for PPP) as a function of the Corruption Perception Index (CPI) for 2002, and Environmental Sustainability Index (ESI) for 2002 as a function of GDP per capita 2000 (adjusted for PPP). CPI: scale from 0 (most corrupt) to 10 (least corrupt). ESI: scale from 0 (least sustainable) to 100 (most sustainable).
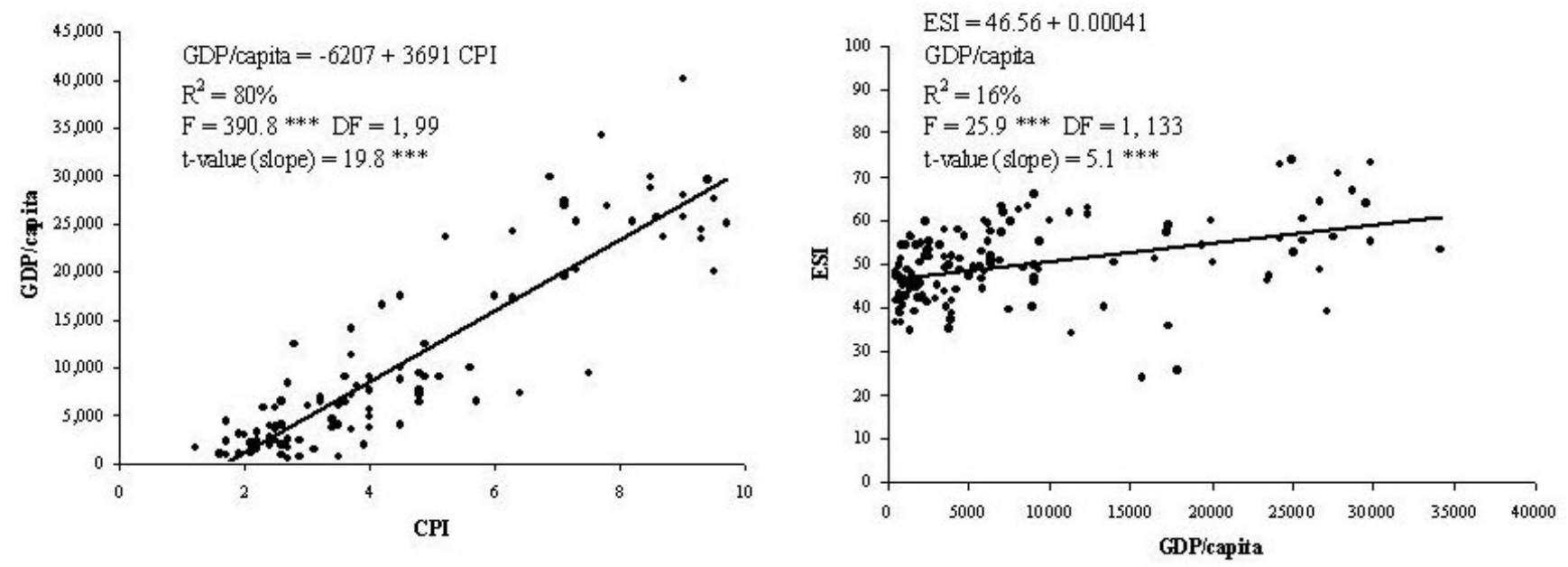

Despite the statistical significance of the $\mathrm{t}$-value of slope $(\mathrm{t}=5.1, \mathrm{P}<0.001)$ the $\mathrm{R}^{2}$ is low $(16 \%)$. Indeed, Morse and Fraser (2005) point out that some ESI components are more strongly related to GDP/ capita than others.

Given that both the CPI and ESI are positively related to GDP per capita then the ESI can also be related to the CPI. Figure 2 shows plots of CPI (independent variable) and ESI (dependent variable) for 2001, 2002, and 2004-05. The data set is limited by availability of values for both the ESI and the CPI over those years, hence the residual degrees of freedom are only 82 . Even so all three linear regressions are highly significant with $\mathrm{R}^{2}$ varying from $30 \%$ up to $65 \%$. Though there is substantial unexplained variation (up to $70 \%$ ), the evidence for at least some relationship between corruption and environmental sustainability appears to be compelling. As corruption lessens (CPI increases) then environmental sustainability as measured by the ESI improves (ESI increases). Of course the graphs say nothing about the causes of the relationship. There may well be direct effects (e.g., corruption limiting the introduction of regulations or the effectiveness of enforcement) as well as indirect (acting through income). Given that the ESI values in Figure 2 are composites of between 67 and 76 variables it could reasonably be hypothesized that only some of the variables may be responsible. Does a more indepth analysis using the PSIR framework shed some light on the causes of the relationship between ESI and CPI?

\section{PSIR components of the ESI related to the CPI}

Assuming the PSIR indicators have an element of cause-effect (pressure influences state which in turn influences impact), Table 3 presents the correlation coefficients between the indicators. It should be remembered that higher values of the indicators always point towards greater sustainability. Many of the correlations are significant and positive; as one indicator shows an increasing sustainability then so does the other. For example, VULHEA (an indicator of environmental health) increases in line with SYSAIR (air quality) and SYSWQL (water quality). This is a logical relationship as increases in air and water quality would presumably reduce the variables that comprise the indicator: death rate from intestinal infectious diseases, child death rate 
Fig. 2. Environmental Sustainability Index (ESI) as a function of Corruption Perception Index (CPI). CPI: scale from 0 (most corrupt) to 10 (least corrupt). ESI: scale from 0 (least sustainable) to 100 (most sustainable).
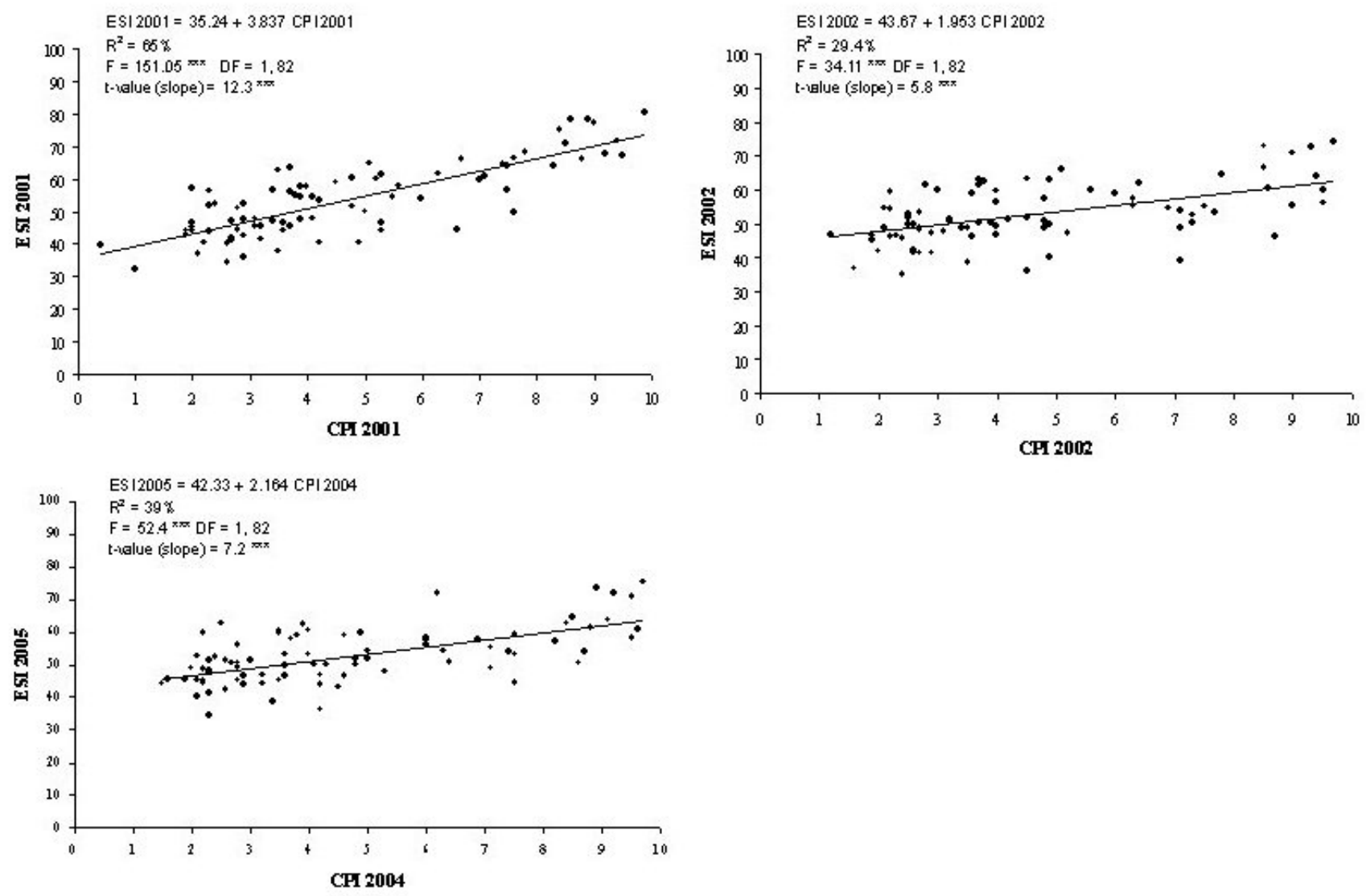

from respiratory diseases, and children under five mortality rate per 1,000 live births. However, it should be noted that some coefficients in Table 3 are negative, implying that an increase in sustainability suggested by one indicator leads to a decrease in sustainability in the other. Good examples of an apparent breakdown in cause-effect can be found under Table 3.1, the correlations between pressure and state indicators. SYSAIR is negatively correlated with STRAIR implying that air quality increases (SYSAIR increases) as the pressure brought about by emissions increases (STRAIR declines). There may well be differences in data quality here as Welsch (2004) suggests, but another complicating factor in all the correlations in Table 3 is the relationship the indicators have to income, which can be strong. Table 4 are the correlation coefficients between the indicators and income as proxied by logarithm of GDP per capita. Most of the pressure indicators have a negative correlation to income (pressure worsens as income increases) but the opposite is true for most of the state, impact, and response indicators. Given that the number of state, impact, and response indicators outnumbers the number of pressure indicators, the ESI increases with income (Figure 1). This, however, may hide the worsening pressure on the environment.

Corruption, as measured by the CPI, is also highly correlated with income (Figure 1) such that corruption tends to worsen (CPI declines) with 
Table 3. Correlation coefficients for the PSIR components of the ESI 2002 data set.

3.1 State indicators as a function of presure indicators

\begin{tabular}{|c|c|c|c|c|c|c|c|c|}
\hline \multicolumn{9}{|c|}{ Pressure } \\
\hline State & STRAIR & STRWAT & STRECO & STRWAS & STRPOP & GLOCLI & GLOTRA & \\
\hline $\begin{array}{l}\text { SYSA- } \\
\text { IR }\end{array}$ & $-0.296 * * *$ & $-0.218 *$ & $0.008 \mathrm{~ns}$ & $-0.48 * * *$ & $0.558 * * *$ & $-0.353 * * *$ & $-0.071 \mathrm{~ns}$ & $\begin{array}{c}\text { Air } \\
\text { Quality }\end{array}$ \\
\hline $\begin{array}{l}\text { SYS- } \\
\text { WQN }\end{array}$ & $0.229 *$ & $0.338 * * *$ & $0.214 *$ & $-0.01 \mathrm{~ns}$ & $-0.036 \mathrm{~ns}$ & $0.094 \mathrm{~ns}$ & $0.171 \mathrm{~ns}$ & $\begin{array}{l}\text { Water Qu- } \\
\text { antity }\end{array}$ \\
\hline $\begin{array}{l}\text { SYS- } \\
\text { WQL }\end{array}$ & $-0.111 \mathrm{~ns}$ & $0.133 \mathrm{~ns}$ & $-0.102 \mathrm{~ns}$ & $-0.586 * * *$ & $0.414 * * *$ & $-0.174 \mathrm{~ns}$ & $-0.074 \mathrm{~ns}$ & $\begin{array}{l}\text { Water } \\
\text { Quality }\end{array}$ \\
\hline $\begin{array}{l}\text { SYSB- } \\
\text { IO }\end{array}$ & $0.136 \mathrm{~ns}$ & $0.167 \mathrm{~ns}$ & $-0.036 \mathrm{~ns}$ & $0.167 \mathrm{~ns}$ & $-0.099 \mathrm{~ns}$ & $-0.032 \mathrm{~ns}$ & $0.28 * *$ & Biodiversity \\
\hline \multirow{2}{*}{$\begin{array}{l}\text { SYSL- } \\
\text { AN }\end{array}$} & $0.415 * * *$ & $0.338 * * *$ & $0.473 * * *$ & $0.277 * *$ & $-0.409 * * *$ & $0.184 \mathrm{~ns}$ & $-0.035 \mathrm{~ns}$ & Land \\
\hline & $\begin{array}{l}\text { Reducing Air } \\
\text { Pollution }\end{array}$ & $\begin{array}{l}\text { Reducing W- } \\
\text { ater Stress }\end{array}$ & $\begin{array}{l}\text { Reducing } \\
\text { Ecosystem } \\
\text { Stress }\end{array}$ & $\begin{array}{l}\text { Reducing } \\
\text { Waste \& } \\
\text { Consumption } \\
\text { Pressures }\end{array}$ & $\begin{array}{l}\text { Reducing } \\
\text { Population } \\
\text { Pressure }\end{array}$ & $\begin{array}{c}\text { Greenhouse Gas } \\
\text { Emissions }\end{array}$ & $\begin{array}{c}\text { Reducing Trans- } \\
\text { boundary Envir- } \\
\text { onmental Press- } \\
\text { ures }\end{array}$ & \\
\hline
\end{tabular}

3.2 Impact indicators as a function of state indicators

\begin{tabular}{lcccccc}
\hline \hline \multicolumn{1}{c}{ SYSAIR } & SYSWQN & SYSWQL & SYSBIO & SYSLAN \\
\hline Impact & SYate & & \\
VULSUS & $0.462 * * *$ & $0.054 \mathrm{~ns}$ & $0.414 * * *$ & $0.013 \mathrm{~ns}$ & $-0.258 *$ & Basic Human Sustenance \\
VULHEA & $0.62 * * *$ & $0.044 \mathrm{~ns}$ & $0.445 * * *$ & $-0.107 \mathrm{~ns}$ & $-0.353 * * *$ & Environmental Health \\
& Air Quality & Water Quantity & Water Quality & Biodiversity & Land & \\
& & & & & &
\end{tabular}

3.3 Presure indicators as a function of response indicators

\begin{tabular}{lccccccc}
\hline \hline \multicolumn{7}{c}{ Response } \\
\hline Pressure & CAPST & CAPEFF & CAPDEB & CAPGOV & CAPPRI & GLOPAR \\
STRAIR & $-0.589 * * *$ & $0.237 *$ & $-0.225 *$ & $-0.481 * * *$ & $-0.314 * *$ & $-0.481 * * *$ & Reducing Air \\
& & & & & & & Pollution \\
\hline
\end{tabular}




\begin{tabular}{|c|c|c|c|c|c|c|c|}
\hline STRWAT & $-0.382 * * *$ & $0.259 *$ & $-0.072 \mathrm{~ns}$ & $-0.237 *$ & $-0.261 *$ & $-0.239 *$ & Reducing Water Stress \\
\hline STRECO & $-0.146 \mathrm{~ns}$ & $-0.128 \mathrm{~ns}$ & $-0.099 \mathrm{~ns}$ & $-0.237 *$ & $-0.207 *$ & $-0.302 * *$ & $\begin{array}{c}\text { Reducing Ecosystem } \\
\text { Stress }\end{array}$ \\
\hline STRWAS & $-0.79 * * *$ & $0.304 * *$ & $-0.316 * *$ & $-0.555 * * *$ & $-0.422 * * *$ & $-0.497 * * *$ & $\begin{array}{c}\text { Reducing Waste \& } \\
\text { Consumption Pressures }\end{array}$ \\
\hline STRPOP & $0.696 * * *$ & $-0.494 * *$ & $0.218 *$ & $0.354 * * *$ & $0.386 * * *$ & $0.377 * * *$ & $\begin{array}{c}\text { Reducing Population } \\
\text { Pressure }\end{array}$ \\
\hline GLOCLI & $-0.563 * * *$ & $0.804 * * *$ & $-0.099 \mathrm{~ns}$ & $-0.136 \mathrm{~ns}$ & $-0.177 \mathrm{~ns}$ & $-0.231 *$ & $\begin{array}{c}\text { Greenhouse Gas } \\
\text { Emissions }\end{array}$ \\
\hline \multirow[t]{2}{*}{ GLOTRA } & $-0.228 *$ & $0.153 \mathrm{~ns}$ & $0.179 \mathrm{~ns}$ & $-0.117 \mathrm{~ns}$ & $-0.034 \mathrm{~ns}$ & $-0.292 * *$ & $\begin{array}{c}\text { Reducing Trans- } \\
\text { boundary Environmental } \\
\text { Pressures }\end{array}$ \\
\hline & $\begin{array}{l}\text { Science and } \\
\text { Technology }\end{array}$ & Eco-Efficiency & $\begin{array}{l}\text { Capacity for } \\
\text { debate }\end{array}$ & $\begin{array}{l}\text { Environmental } \\
\text { Governance }\end{array}$ & $\begin{array}{l}\text { Private Sector } \\
\text { Responsiveness }\end{array}$ & $\begin{array}{l}\text { Participation in } \\
\text { International Col- } \\
\text { laborative Efforts }\end{array}$ & \\
\hline
\end{tabular}

ns not significant at $\mathrm{P}<0.05 * \mathrm{P}<0.05 * * \mathrm{P}<0.01 * * * \mathrm{P}<0.001$

decreasing income. This creates a dilemma when attempting to regress the indicators on the CPI. Is any trend due to income or corruption? For the purpose of this paper, the issue was addressed by first regressing the CPI 2002 on logarithm of GDP per capita and then calculating the predicted CPI values before finding the residuals (observed minus predicted). The results of this correction in CPI are shown in Table 5. In essence, the residual CPI values are a measure of corruption with the influence of income removed. Higher values of the residual CPI correspond to data points where the observed CPI is greater than that predicted from income and vice versa. As a result, the higher the residual CPI, the lower the perception of corruption. It was the residual CPIs that were used as the independent variable in the analysis of PSIR indicators, and the results are shown in Table 6.

Once income has been accounted for, none of the pressure, state, and impact indicators are significant at $5 \%$ and the $\mathrm{R}^{2}$ values are very low (3\% or less). Thus it would appear that corruption is not a good predictor of environmental sustainability. However, there are two regressions that are significant at $10 \%$ (albeit with low $\mathrm{R}^{2}$ ); these are STRPOP (reducing population growth) and VULHEA. In both cases, the slope coefficient is negative suggesting that sustainability worsens (indicators decline) as corruption diminishes (residual CPI increases). VULHEA comprises three variables that measure human health while STRPOP has two variables, which are the percentage change in projected population from 2000 to 2050 and the total fertility rate. The two variables are highly and positively correlated $(\mathrm{r}=0.857 * * *)$ suggesting that as one improves (in a sustainability sense) then so does the other. While it is possible to see how these two indicators could be related to each other and to corruption, it is hard to see why the relationship for the latter would be negative.

However, the indicators that have the most statistically significant relationship to the CPI residuals are those of response. All of them are significant at $10 \%$ and most at $5 \%$, and the regression coefficients are all positive. Values of $\mathrm{R}^{2}$ are not particularly high, although for three of them they are greater than $10 \%$. The three indicators with most statistically significant relationship to the CPI residual are CAPGOV (environmental governance), CAPPRI (private sector responsiveness), and GLOPAR (participation in international collaborative efforts). It is with these that the negative effects of corruption appear to be most felt, and this would appear to be logical given that these indicators may more closely reflect the impact of corrupt behaviour in decision making. CAPGOV comprises amongst 
Table 4. Correlation coefficients for the PSIR components of the ESI 2002 and logarithm GDP 2000.

\begin{tabular}{|c|c|c|c|c|c|}
\hline & Pressure & & & Impact & Response \\
\hline $\begin{array}{l}\text { STR- } \\
\text { AIR }\end{array}$ & $-0.555 * * *$ & SYSAIR & $0.636 * * *$ & $\begin{array}{l}\text { VU- } 0.818 * * * \\
\text { LSUS }\end{array}$ & $\begin{array}{l}\text { CA- } 0.891 * * * \\
\text { PST }\end{array}$ \\
\hline $\begin{array}{l}\text { STR- } \\
\text { WAT }\end{array}$ & $-0.436^{* * *}$ & SYSWQN & $0.056 \mathrm{~ns}$ & $\begin{array}{l}\text { VU- } 0.841 * * * \\
\text { LHE- } \\
\text { A }\end{array}$ & $\begin{array}{l}\text { CA- }-0.233^{*} \\
\text { PE- } \\
\text { FF }\end{array}$ \\
\hline $\begin{array}{l}\text { STR- } \\
\text { ECO }\end{array}$ & $-0.094 \mathrm{~ns}$ & SYSWQL & $0.544 * * *$ & & $\begin{array}{l}\text { CA- } 0.421 * * * \\
\text { PD- } \\
\text { EB }\end{array}$ \\
\hline $\begin{array}{l}\text { STR- } \\
\text { WAS }\end{array}$ & $-0.759 * * *$ & SYSBIO & $-0.097 \mathrm{~ns}$ & & $\begin{array}{l}\text { CA- } 0.656 * * * \\
\text { PG- } \\
\text { OV }\end{array}$ \\
\hline $\begin{array}{l}\text { STR- } \\
\text { POP }\end{array}$ & $0.752 * * *$ & SYSLAN & $-0.3 * *$ & & $\begin{array}{l}\text { CA- } 0.579 * * * \\
\text { PPRI }\end{array}$ \\
\hline $\begin{array}{l}\text { GL- } \\
\text { OCLI }\end{array}$ & $-0.503 * * *$ & & & & $\begin{array}{l}\text { GL- } 0.592 * * * \\
\text { OP- } \\
\text { AR }\end{array}$ \\
\hline $\begin{array}{l}\text { GL- } \\
\text { OT- } \\
\text { RA }\end{array}$ & $-0.264 * *$ & & & & \\
\hline
\end{tabular}

other variables ones such as the World Economic Forum Survey on environmental governance, the number of sectoral EIA guidelines, and the percentage of total land area under protected status. Also included in CAPGOV is a measure of corruption, which is expected to be correlated with the CPI residual, but this is but one of 10 variables. CAPPRI comprises variables such as the World Economic Forum Survey on private sector environmental innovation and the number of ISO 14001 certified companies per billion dollars GDP. GLOPAR has variables such as the number of memberships in environmental intergovernmental organizations, the percentage of CITES reporting requirements met, and compliance with international agreements. It is not difficult to envisage how all of these could be a function of bad decision making, part of which could be due to corruption. 
Table 5. Calculation of residual CPI based upon a regression of CPI 2002 and logarithm GDP per capita for 2000 .

CPI: scale of 0 (most corrupt) to 10 (least corrupt).

\begin{tabular}{|c|c|c|c|c|}
\hline & & Predicted & Residual & \\
\hline Country & CPI 2002 & CPI & CPI & Log GDP/capita \\
\hline Albania & 2.5 & 3.4548 & -0.9548 & 3.5448 \\
\hline Angola & 1.7 & 2.6286 & -0.9286 & 3.3398 \\
\hline Argentina & 2.8 & 5.6629 & -2.8629 & 4.0926 \\
\hline Australia & 8.6 & 6.9415 & 1.6585 & 4.4098 \\
\hline Austria & 7.8 & 7.0131 & 0.7869 & 4.4276 \\
\hline Azerbaijan & 2 & 3.1442 & -1.1442 & 3.4678 \\
\hline Bangladesh & 1.2 & 2.0837 & -0.8837 & 3.2047 \\
\hline Belgium & 7.1 & 7.0399 & 0.0601 & 4.4342 \\
\hline Bolivia & 2.2 & 2.8087 & -0.6087 & 3.3845 \\
\hline Botswana & 6.4 & 4.7106 & 1.6894 & 3.8564 \\
\hline Brazil & 4 & 4.8149 & -0.8149 & 3.8822 \\
\hline Bulgaria & 4 & 4.3086 & -0.3086 & 3.7566 \\
\hline Cameroon & 2.2 & 2.1907 & 0.0093 & 3.2312 \\
\hline Canada & 9 & 7.0820 & 1.9180 & 4.4447 \\
\hline Chile & 7.5 & 5.1844 & 2.3156 & 3.9739 \\
\hline
\end{tabular}




\begin{tabular}{|c|c|c|c|c|}
\hline China & 3.5 & 3.6750 & -0.1750 & 3.5994 \\
\hline Colombia & 3.6 & 4.4663 & -0.8663 & 3.7957 \\
\hline Costa Rica & 4.5 & 5.0357 & -0.5357 & 3.9370 \\
\hline Cote d'Ivoire & 2.7 & 2.1140 & 0.5860 & 3.2122 \\
\hline Croatia & 3.8 & 4.9188 & -1.1188 & 3.9080 \\
\hline Czech Republic & 3.7 & 5.8775 & -2.1775 & 4.1458 \\
\hline Denmark & 9.5 & 7.0686 & 2.4314 & 4.4413 \\
\hline Dominican Rep. & 3.5 & 4.4050 & -0.9050 & 3.7805 \\
\hline Ecuador & 2.2 & 3.2965 & -1.0965 & 3.5056 \\
\hline Egypt & 3.4 & 3.5180 & -0.1180 & 3.5605 \\
\hline El Salvador & 3.4 & 3.8906 & -0.4906 & 3.6529 \\
\hline Estonia & 5.6 & 5.3011 & 0.2989 & 4.0029 \\
\hline Ethiopia & 3.5 & 0.5524 & 2.9476 & 2.8248 \\
\hline Finland & 9.7 & 6.8934 & 2.8066 & 4.3979 \\
\hline France & 6.3 & 6.8384 & -0.5384 & 4.3842 \\
\hline Germany & 7.3 & 6.9009 & 0.3991 & 4.3997 \\
\hline Ghana & 3.9 & 2.4403 & 1.4597 & 3.2931 \\
\hline Greece & 4.2 & 6.1664 & -1.9664 & 4.2175 \\
\hline Guatemala & 2.5 & 3.6054 & -1.1054 & 3.5822 \\
\hline Haiti & 2.2 & 1.9296 & 0.2704 & 3.1664 \\
\hline
\end{tabular}




\begin{tabular}{|c|c|c|c|c|}
\hline Honduras & 2.7 & 2.8295 & -0.1295 & 3.3897 \\
\hline Hungary & 4.9 & 5.6684 & -0.7684 & 4.0940 \\
\hline Iceland & 9.4 & 7.1882 & 2.2118 & 4.4710 \\
\hline India & 2.7 & 2.7604 & -0.0604 & 3.3725 \\
\hline Indonesia & 1.9 & 3.2068 & -1.3068 & 3.4833 \\
\hline Ireland & 6.9 & 7.2050 & -0.3050 & 4.4752 \\
\hline Israel & 7.3 & 6.5145 & 0.7855 & 4.3039 \\
\hline Italy & 5.2 & 6.7947 & -1.5947 & 4.3734 \\
\hline Jamaica & 4 & 3.5200 & 0.4800 & 3.5610 \\
\hline Japan & 7.1 & 7.0124 & 0.0876 & 4.4274 \\
\hline Jordan & 4.5 & 3.6706 & 0.8294 & 3.5984 \\
\hline Kazakhstan & 2.3 & 4.3573 & -2.0573 & 3.7687 \\
\hline Kenya & 1.9 & 1.2968 & 0.6032 & 3.0095 \\
\hline Latvia & 3.7 & 4.6764 & -0.9764 & 3.8479 \\
\hline Lithuania & 4.8 & 4.6915 & 0.1085 & 3.8516 \\
\hline Madagascar & 1.7 & 0.9535 & 0.7465 & 2.9243 \\
\hline Malawi & 2.9 & 0.4077 & 2.4923 & 2.7889 \\
\hline Malaysia & 4.9 & 5.1183 & -0.2183 & 3.9575 \\
\hline Mexico & 3.6 & 5.1096 & -1.5096 & 3.9554 \\
\hline Moldova & 2.1 & 2.5650 & -0.4650 & 3.3241 \\
\hline
\end{tabular}




\begin{tabular}{|c|c|c|c|c|}
\hline Morocco & 3.7 & 3.4746 & 0.2254 & 3.5497 \\
\hline Namibia & 5.7 & 4.5168 & 1.1832 & 3.8083 \\
\hline Netherlands & 9 & 6.9391 & 2.0609 & 4.4092 \\
\hline New Zealand & 9.5 & 6.5091 & 2.9909 & 4.3025 \\
\hline Nicaragua & 2.5 & 2.7663 & -0.2663 & 3.3740 \\
\hline Nigeria & 1.6 & 1.0665 & 0.5335 & 2.9523 \\
\hline Norway & 8.5 & 7.2080 & 1.2920 & 4.4759 \\
\hline Pakistan & 2.6 & 2.4079 & 0.1921 & 3.2851 \\
\hline Panama & 3 & 4.3953 & -1.3953 & 3.7782 \\
\hline Paraguay & 1.7 & 3.8627 & -2.1627 & 3.6460 \\
\hline Peru & 4 & 4.0044 & -0.0044 & 3.6812 \\
\hline Philippines & 2.6 & 3.6728 & -1.0728 & 3.5989 \\
\hline Poland & 4 & 5.1150 & -1.1150 & 3.9567 \\
\hline Portugal & 6.3 & 6.2481 & 0.0519 & 4.2378 \\
\hline Romania & 2.6 & 4.5146 & -1.9146 & 3.8077 \\
\hline Russia & 2.7 & 4.9796 & -2.2796 & 3.9231 \\
\hline Senegal & 3.1 & 1.9801 & 1.1199 & 3.1790 \\
\hline Slovak Republic & 3.7 & 5.4947 & -1.7947 & 4.0509 \\
\hline Slovenia & 6 & 6.2559 & -0.2559 & 4.2397 \\
\hline South Africa & 4.8 & 5.1815 & -0.3815 & 3.9732 \\
\hline
\end{tabular}




\begin{tabular}{|c|c|c|c|c|}
\hline South Korea & 4.5 & 6.2572 & -1.7572 & 4.2400 \\
\hline Spain & 7.1 & 6.4562 & 0.6438 & 4.2894 \\
\hline Sri Lanka & 3.7 & 3.4667 & 0.2333 & 3.5478 \\
\hline Sweden & 9.3 & 6.8423 & 2.4577 & 4.3852 \\
\hline Switzerland & 8.5 & 7.1395 & 1.3605 & 4.4589 \\
\hline Tanzania & 2.7 & 0.1240 & 2.5760 & 2.7185 \\
\hline Thailand & 3.2 & 4.5089 & -1.3089 & 3.8063 \\
\hline Trinidad \& Tobago & 4.9 & 5.0981 & -0.1981 & 3.9525 \\
\hline Tunisia & 4.8 & 4.4982 & 0.3018 & 3.8037 \\
\hline Turkey & 3.2 & 4.6587 & -1.4587 & 3.8435 \\
\hline Uganda & 2.1 & 1.5895 & 0.5105 & 3.0821 \\
\hline Ukraine & 2.4 & 3.6031 & -1.2031 & 3.5816 \\
\hline United Kingdom & 8.7 & 6.7860 & 1.9140 & 4.3712 \\
\hline Uruguay & 5.1 & 5.1120 & -0.0120 & 3.9559 \\
\hline USA & 7.7 & 7.4392 & 0.2608 & 4.5333 \\
\hline Uzbekistan & 2.9 & 2.8209 & 0.0791 & 3.3876 \\
\hline Venezuela & 2.5 & 4.3342 & -1.8342 & 3.7630 \\
\hline Vietnam & 2.4 & 2.4686 & -0.0686 & 3.3002 \\
\hline Zambia & 2.6 & 0.8237 & 1.7763 & 2.8921 \\
\hline Zimbabwe & 2.7 & 2.9548 & -0.2548 & 3.4208 \\
\hline
\end{tabular}


Predicted CPI is based on a regression of CPI 2002 and logarithm GDP/capita for 2000.

Regression equation:

$\mathrm{CPI}=-10.884+4.0309 \log (\mathrm{GDP} /$ capita $)$

$\mathrm{t}$-value $($ intercept $)=-9.63 * * * *$

$\mathrm{t}$-value $($ slope $)=13.67 * * *$

\section{DISCUSSION}

What does this analysis say about the effect of corruption on environmental sustainability? First, it needs to be reiterated that it is an analysis of indicators and indices that are meant to be representations of an underlying truth. The CPI does not measure corruption in the same sense that a pollutant can be measured in water. As the ESI has been criticized for not taking into account flows of pollutants across national borders (The Ecologist 2001) then it is well to remember that causes of corruption are not necessarily all internal. Hisamatsu (2003) has shown how corruption within a country can be enhanced by foreign demand. The CPI is largely an index of the perception of business people, mostly based in the developed world and this cannot be assumed to be an unbiased group. Their perception of corruption across countries could well be formed by a range of factors, including stories (possibly exaggerated) they may hear from their colleagues. The measure of corruption is being made by those who may, at least in part, be enhancing the very characteristic they are experiencing and reporting. Both environmental sustainability and corruption are transnational, and the allocation of single values to countries can hide such globalization. Similarly, the ESI is a collection of indicators which in turn are amalgams of variables. This choice plus the methodologies for handling the data have been set by the creators of the ESI. The categorization of indicators into PSIR for this paper was the choice of the author and not of the creators of the ESI. Thus, it is important to remember that the apparent objectivity of the analyses in the tables and figures is based on much subjective judgment.

The results broadly suggest that the only significant relations between CPI and the ESI indicators are with those in the response category, although even here the $\mathrm{R}^{2}$ values are less than $20 \%$. There were some marginally significant relationships between the CPI and pressure and impact indicators (notably STRPOP and VULHEA), but it is with the response indicators that the effects are most readily apparent. The link between response and corruption should perhaps be expected, given that the nature of many of the variables that comprise the response indicators and their direct relationship to the senior decision makers (who could well be representative of the groups most likely to be met by the business people whose views form the basis of the CPI). While it may appear that reducing corruption improves decision making and management, such a simplistic assumption of cause-effect may be misleading. It could be that the response indicators and residual CPI could be manifestations of an underlying quality of policy making and management with many influences. Great care does need to be taken when assuming a cause-effect relationship, especially with factors as complex and multifaceted as environmental sustainability and corruption.

If the response indicators are being influenced, at least in part by corruption, then why does this not feed through into the pressure, state, and impact indicators? After all there were numerous significant correlations amongst the indicators, including those of pressure and response. There could be issues of data quality here as well as sampling and aggregation distortions that might arise from trying to allocate a single value for ambient pollution or emissions for each country. The single figures for each country could hide a substantial degree of intra-country variation with a patchwork of good and bad environmental conditions. There is simply too much error variation in the data once the effect of income has been removed, and while some significant trends can be discerned the explanatory power of those 
Table 6. Regression analysis with the PSIR indicators as dependent variables and residual CPI as the independent variable. Numbers shown are the t-values for the coefficients along with statistical significance.

6.1 Pressure (7 indicators and 21 variables)

\begin{tabular}{|c|c|c|c|c|}
\hline Indicator & Description & Intercept & Slope & Adjusted $\mathrm{R}^{2}$ \\
\hline STRAIR & Reducing Air Pollution & $-0.10(0.089) \mathrm{ns}$ & $-0.086(0.067) \mathrm{ns}$ & 0.7 \\
\hline STRWAT & Reducing Water Stress & $0.001(0.064) \mathrm{ns}$ & $-0.01(0.048) \mathrm{ns}$ & 0 \\
\hline STRECO & Reducing Ecosystem Stress & $-0.059(0.063) \mathrm{ns}$ & $-0.029(0.048) \mathrm{ns}$ & 0 \\
\hline STRWAS & $\begin{array}{c}\text { Reducing Waste } \& \text { Consumption } \\
\text { Pressures }\end{array}$ & $-0.033(0.089) \mathrm{ns}$ & $-0.071(0.067) \mathrm{ns}$ & 0.1 \\
\hline STRPOP & Reducing Population Pressure & $0.311(0.08) \mathrm{ns}$ & $-0.112(0.06) \mathrm{P}=0.065$ & 2.6 \\
\hline GLOCLI & Greenhouse Gas Emissions & $-0.054(0.082) \mathrm{ns}$ & $0.072(0.062) \mathrm{ns}$ & 0.4 \\
\hline GLOTRA & $\begin{array}{l}\text { Reducing Trans-boundary } \\
\text { Environmental Pressures }\end{array}$ & $-0.107(0.067) \mathrm{ns}$ & $0.024(0.051) \mathrm{ns}$ & 0 \\
\hline
\end{tabular}

6.2 State (5 indicators and 13 variables)

\begin{tabular}{lcccc}
\hline \hline Indicator & Description & Intercept & Slope & Adjusted $\mathrm{R}^{2}$ \\
\hline SYSAIR & Air Quality & $0.218(0.072) * *$ & $0.082(0.054) \mathrm{ns}$ & 1.4 \\
SYSWQN & Water Quantity & $-0.036(0.071) \mathrm{ns}$ & $-0.035(0.054) \mathrm{ns}$ & 0 \\
SYSWQL & Water Quality & $0.197(0.062) * *$ & $0.069(0.046) \mathrm{ns}$ & 1.3 \\
SYSBIO & Biodiversity & $-0.077(0.096) \mathrm{ns}$ & $-0.039(0.072) \mathrm{ns}$ & 0 \\
SYSLAN & Land & $-0.156(0.091) \mathrm{P}=0.088$ & $0.075(0.068) \mathrm{ns}$ & 0.2 \\
\hline
\end{tabular}

6.3 Impact (2 indicators and 5 variables)

\begin{tabular}{lcccc}
\hline \hline Indicator & Description & Intercept & Slope & Adjusted $\mathrm{R}^{2}$ \\
\hline VULSUS & Basic Human Sustenance & $0.251(0.08) * *$ & $-0.055(0.06) \mathrm{ns}$ & 0 \\
VULHEA & Environmental Health & $0.312(0.081) * * *$ & $-0.12(0.061) \mathrm{P}=0.051$ & 3 \\
\hline
\end{tabular}

6.4 Response (6 indicators and 29 variables)

\begin{tabular}{lcccc}
\hline \hline Indicator & Description & Intercept & Slope & Adjusted R $^{2}$ \\
\hline CAPST & Science and Technology & $0.038(0.09) \mathrm{ns}$ & $0.126(0.068) \mathrm{P}=0.066$ & 2.5 \\
CAPEFF & Eco-Efficiency & $-0.002(0.071) \mathrm{ns}$ & $0.123(0.053) *$ & 4.4
\end{tabular}




\begin{tabular}{lcccc}
\hline CAPDEB & Capacity for debate & $0.121(0.05) *$ & $0.097(0.038) *$ & 5.7 \\
CAPGOV & Environmental Governance & $0.083(0.059) \mathrm{ns}$ & $0.212(0.044) * * *$ & 19.1 \\
CAPPRI & Private Sector Responsiveness & $-0.012(0.072) \mathrm{ns}$ & $0.234(0.054) * * *$ & $0.154(0.038) * * *$ \\
GLOPAR & $\begin{array}{c}\text { Participation in International } \\
\text { Collaborative Efforts }\end{array}$ & $0.156(0.051) * *$ & & 13.7 \\
& & & & \\
& & &
\end{tabular}

ns not significant at $\mathrm{P}<0.05 * \mathrm{P}<0.05 * * \mathrm{P}<0.01 * * * \mathrm{P}<0.001$

regressions in this analysis is low.

Returning to the cause-effect issue, all of the graphs in this paper present the ESI and its components as dependent variables and corruption as independent. This is a reflection of Welsch (2004): "corruption reduces income, and lower income goes along with higher pollution levels". Hence there is a clear linear chain of thinking. The problem is that corruption could be encouraged by low income levels as well as a poor environment. The latter could be reflected, for example, in a wish to escape from polluted spaces to more affluent spaces where these problems may generally be less. After all, it only takes a relative few individuals in important positions where they have contact with foreigners to generate perception of corruption reflected in the CPI. This results in a complex positive feedback model and the developed world is not without responsibility. Is environmental sustainability (ESI) now a function of corruption (CPI) or should this relationship be reversed? The answer is probably an element of both.

\section{CONCLUSION}

While the results of this research do superficially suggest a significant relationship between corruption and environmental sustainability, care needs to be taken with interpretation even when regressions are statistically significant. Even the best regressions have $\mathrm{R}^{2}$ values of less than $20 \%$, but perhaps this is not surprising given the data sets that form the basis of the analysis. Highly aggregated (on a spatial scale) indices such as the ESI and CPI can hide much intracountry variation. The ESI in particular has had its share of critics with regard to the choice of variables and methods of mathematical integration. The CPI is a measure of perception of but one group of stakeholders, mostly based in the developed world. Given all these issues it is perhaps surprising that any statistically significant relationships emerge between the CPI and some of the ESI indicators.

While the analyses presented in this paper provide some clues as to the relationship between corruption and environmental sustainability, care does need to be exercised. This relationship requires much further exploration with a diverse range of methods and not just the sort of highly aggregated, quantitative, and national data employed here. More qualitative case studies could generate insights that would help with the interpretation of the national studies. If we have learned anything about sustainability, it is how variables can be intertwined in complex relationships, which are highly resistant to simplification.

Responses to this article can be read online at: http://www.ecologyandsociety.org/voll1/iss1/art22/responses/

\section{Acknowledgments:}

I would like to thank the two anonymous referees for their constructive comments with regards to the improvement of this paper.

\section{LITERATURE CITED}

Berger, A. R. 1997. Natural Environmental Change: a challenge to the DSR approach. Pages 191-197 in B. Moldan, S. Billharz, and R. Matravers, editors. Sustainability Indicators: A Report on the Project on Indicators of Sustainable 
Development. John Wiley and Sons, Chichester, UK.

Carter, T. S. 1997. The failure of environmental regualiton in New York: the role of co-optation, corruption, and a co-operative enforcement approach. Crime Law and Social Change 26 (1):27-52.

Chiesura, A., and R. De Groot. 2003. Critical natural capital: a socio-cultural perspective. Ecological Economics 44(2-3):219-231.

Crabtree, B., and N. Bayfield. 1998. Developing Sustainability Indicators for Mountain Ecosystems: a study of the Cairngorms, Scotland. Journal of Environmental Management 52:1-14.

Damania, R., P. G. Fredriksson, and J. A. List. 2003. Trade liberalization, corruption, and environmental policy formulation: theory and evidence. Journal of Environmental Economics and Management 46(3):490-512.

Davies, H. 2004. Dossier of dirty deeds. The Times Higher Educational Supplement. TSL Education, London, United Kingdom.

De Groot, R., J. Van der Perk, A. Chiesura, A., and S. van Vliet. 2003. Importance and threat as determining factors for criticality of natural capital. Ecological Economics 44(2-3):187-204.

Deutsch, L., C. Folke, and K. Skanberg. 2003. The critical natural capital of ecosystem performance as insurance for human well-being. Ecological Economics 44 (2-3):205-217.

Doig, A., and S. McIvor. 1999. Corruption and its control in the developmental context: an analysis and selective review of the literature. Third World Quarterly 20(3):657-676.

Economist. 2002. The Environmental Sustainability Index. 362(8264).

Ekins, P., and S. Simon. 2003. An illustratvive application of the CRITINC framework to the UK. Ecological Economics 44(2-3):255-275.

Ekins, P., S. Simon, L. Deutsch, C. Kolke, and R. De Groot. 2003. A framework for the practical application of the concepts of critical natural capital and strong sustainability. Ecological Economics 44
(2-3):165-195.

Esty, D. 2005. Top of the greens. New Scientist 2485.

Esty, D. C., A. Marc Levy, T. Srebotnjak, and A. de Sherbinin. 2005. 2005 Environmental Sustainability Index: Benchmarking National Environmental Stewardship. Yale Center for Environmental Law and Policy, New Haven, Conneticut, USA.

Gallopin, G. C. 1997. Indicators and Their Use: information for decision-making. Pages 13-27 in B. Moldan, S. Billharz, and R. Matravers, editors. Sustainability Indicators: A Report on the Project on Indicators of Sustainable Development. John Wiley and Sons, Chichester, UK.

Goudie, A. W., and D. Stasavage. 1998. A framework for the analysis of corruption. Crime Law and Social Change 29(2-3):113-159.

Grossman, G. M., and A. B. Krueger. 1995. Economic growth and the environment. The Quarterly Journal of Economics 110(2):353-377.

Guy, G. B., and C. J. Kibert. 1998. Developing Indicators of Sustainability: US experience. Building Research and Information 26(1):39-45.

Hall, R., and C. Jones. 1999. Why do some countries produce so much more output per worker than others? Quarterly Journal of Economics 114:83-116.

Hisamatsu, Y. 2003. Does foreign demand affect corruption? Applied Economics Letters 10(1):1-2.

Jesinghaus, J. 2000. The World Economic Forum's Environmental Sustainability Index: strong and weak points Ispra, Italy. Joint Research Centre of the European Commission, Brussels, Belgium.

Lambsdorff, J. G. 1999. Corruption in Empirical Research: a review. Working Paper. Transparency International and Göttingen University, Germany. [online] URL: http://ww1.transparency.org/ working_papers/lambsdorff/lambsdorff_eresearch. html.

Lambsdorff, J. G. 2002. Background paper to the 2002 Corruption Perceptions Index. Framework Document 2002. Transparency International and 
Göttingen University, Germany. [online] URL: http://ww1.transparency.org/cpi/2002/dnld/cpi2002. methodology.pdf.

Lopez, R., and S. Mitra. 2000. Corruption, pollution, and the Kuznets environment curve. Journal of Environmental Economics and Management 40(2):137-150.

Mauro, P. 1995. Corruption and growth. The Quarterly Journal of Economics 110(3):681-712.

Morse, S. 2004. Indices and indicators in development. An unhealthy obsession with numbers? Earthscan, London, UK.

Mortensen, L. F. 1997. The Driving Force-StateResponse Framework used by CSD. Pages 47-53 in B. Moldan, S. Billharz, and R. Matravers, editors. Sustainability Indicators: A Report on the Project on Indicators of Sustainable Development. John Wiley and Sons, Chichester, UK.

Robbins, P. 2000. The rotten institution: corruption in natural resource management. Political Geography 19(4):423-443.

Spangenberg, J. H., and O. Bonniot. 1998. Sustainability Indicators: A Compass on the Road Towards Sustainability. Wuppertal Institute for Climate, Environment, and Energy, Wuppertal, Germany. [online] URL: http://www.wupperinst. org/Publikationen/WP/WP81.pdf

Sutton, P. C., and R. Costanza. 2002. Global estimates of market and non-market values derived from nighttime satellite imagery, land use, and ecosystem service valuation. Ecological Economics 41:509-527.

The Ecologist and Friends of the Earth. 2001. Keeping score: which countries are the most sustainable? Ecologist 31(3):44.

UNDP. 2002. Human Development Report: deepening democracy in a fragmented world. Oxford University Press, Oxford, UK.

Welsch, H. 2004. Corruption, growth, and the environment: a cross-country analysis. Environment and Development Economics 9:663-693.

World Bank. 1997. The State in a Changing World. World Development Report 1997. Oxford
University Press, Oxford, UK.

Wilhelm, P. G. 2002. International validation of the Corruption Perceptions Index: Implications for business ethics and entrepreneurship education. Journal of Business Ethics 35(3):177-189.

Zemanovicova, D. 2002. Economic aspects of corruption. Ekonomicky Casopis 50(2):182-196.

[1] The Pressure-State-Impact-Response (PSIR) is a widely employed categorization of indicators (Crabtree and Bayfield 1998, Guy and Kibert 1998). 'Pressure' indicators are those that gauge factors such as emission rates of pollutants (e.g., $\mathrm{NO}_{\mathrm{X}}$ into the atmosphere); 'state' indicators gauge the level of the pollutant in the medium (e.g., concentration of $\mathrm{NO}_{\mathrm{X}}$ in air); 'impact' indicators gauge the effect the pollutants may be having (e.g., respiratory disease in humans); 'response' gauges what can be done about the problem in terms of policy, legislation, or management. 